\title{
Aprendizado interprofissional em saúde: experiências curriculares e disponibilidade de estudantes na Universidade Federal do Rio Grande do Sul
}

\author{
Ramona Fernanda Ceriotti, Everson Meireles, Luciane Inês Ely, Marina Peduzzi
}

\begin{abstract}
Resumo
Introdução: Arquiteturas curriculares essencialmente uniprofissionais, que pouco contribuem para uma prática de trabalho interprofissional colaborativa no cuidado em saúde e para o reconhecimento das responsabilidades e papeis das diferentes profissões da saúde, ainda são as mais observadas entre os cursos de graduação em saúde no Brasil. Experiências na graduação envolvendo o 'aprender junto' sobre o trabalho em saúde devem fazer parte dos currículos dos cursos da área da saúde. Nesse contexto, a estratégia pedagógica da educação interprofissional (EIP) apresenta-se como uma necessidade para qualificar tanto a educação quanto as práticas colaborativas em saúde. E EIP é conceituada como uma "atividade que envolve dois ou mais profissionais que aprendem juntos de modo interativo para melhorar a qualidade da atenção à saúde" (REEVES, 2016, p. 185). Entendendo que práticas de trabalho em equipe interprofissionais bem-sucedidas são alcançadas por meio da aprendizagem interprofissional, a Universidade Federal do Rio Grande do Sul (UFRGS), por meio da Coordenadoria da Saúde (CoorSaúde) propõe, em 2012, a atividade de ensino integradora dos cursos da saúde. A atividade é oferecida a cada semestre, como disciplina eletiva ou adicional aos currículos, envolvendo os 14 cursos de graduação da área da saúde (Biomedicina, Ciências Biológicas, Educação Física, Enfermagem, Farmácia, Fisioterapia, Fonoaudiologia, Medicina, Medicina Veterinária, Nutrição, Odontologia, Psicologia, Saúde Coletiva, Serviço Social) e o curso de graduação em Políticas Públicas. A vivência em cenários de prática do Sistema Único de Saúde (SUS)/Atenção Primária à Saúde (APS), junto aos territórios, sua população e trabalhadores das equipes de Saúde da Família, é o dispositivo de aprendizagem. Competências relacionais e para o trabalho em equipe, essenciais para a EIP, são mobilizadas ao longo da experiência (TOASSI; LEWGOY, 2016; BUENO; TSCHIEDEL, 2011). A disciplina integradora transita entre os currículos dos cursos que a compartilham como um movimento de superação e reação ao modelo de educação hegemonicamente uniprofissional e apresenta-se como um potente cenário para o desenvolvimento da EIP (ELY, 2017). Objetivo Identificar experiências interprofissionais/aprendizagem compartilhada nos currículos dos cursos de graduação da área da saúde na UFRGS e avaliar a disponibilidade desses estudantes para o aprendizado interprofissional e colaborativo em saúde. Também faz parte da intencionalidade da pesquisa contribuir para o aperfeiçoamento da validação do instrumento Readiness for Interprofessional Learning Scale (RIPLS). Metodologia Pesquisa de delineamento transversal observacional cuja amostra foi constituída por estudantes de graduação e egressos que tinham experienciado a atividade de ensino integradora no período de 2012 a 2017 e estudantes de graduação do último ano desses cursos em 2017. A coleta de dados envolveu a aplicação on line da versão validada para língua portuguesa da Readiness for Interprofessional Learning Scale (RIPLS) (PEDUZZI et al., 2015) com adaptações que incluíram novos itens à escala, especialmente no Fator 3. As questões estavam distribuídas em três fatores: Trabalho em equipe (Fator 1), Identidade profissional (Fator 2) e Atenção à saúde centrada no paciente (Fator 3). Para conhecer o contexto da disponibilidade dos estudantes para aprendizagem compartilhada com colegas de outras áreas, às questões da escala foram acrescentadas informações sobre os participantes (idade, sexo, escolaridade, curso de graduação, etapa do curso, se está na etapa esperada do curso, conclusão em outro curso de graduação), suas experiências interprofissionais durante a graduação e percepções sobre a atividade de ensino
\end{abstract}


ISSN 2179-6750

integradora dos cursos da saúde. Os dados coletados estão em processo de análise a partir do Programa Statistical Package for the Social Sciences (SPSS), versão 18.0. A dimensionalidade da escala e as frequências das respostas estão sendo avaliadas (resultados parciais). O estudo teve aprovação do Comitê de Ética em Pesquisa (CEP) da UFRGS (CAAE 52635616.2.0000.5347) e contemplou a utilização do Termo de Consentimento Livre e Esclarecido. Resultados Participaram do estudo 369 estudantes de graduação e egressos da UFRGS. Desses, 186 (50,4\%) havia participado da atividade de ensino integradora. A maioria eram mulheres, com 21 a 26 anos, estudantes de graduação, especialmente do último ano do curso. O curso com maior participação na pesquisa foi a Odontologia $(23,6 \%)$ e a Biomedicina foi o de menor participação $(2,7 \%)$. Das atividades vivenciadas durante o currículo, os estágios curriculares e as atividades extracurriculares diversas foram as que mais possibilitaram o compartilhamento e interação com estudantes de outros cursos. A extensão mostrou maior possibilidade de atividades realizadas com estudantes/profissionais de outros cursos $(43,3 \%)$ do que a pesquisa $(36,6 \%)$, ainda que nem sempre o compartilhamento e a interação com estudantes de outros cursos tenham sido relatados nessas experiências. Mais de $80 \%$ dos participantes identificaram a presença alguma atividade interprofissional/aprendizagem compartilhada durante a realização de disciplinas no curso de graduação, principalmente em disciplinas eletivas ou optativas $(56,7 \%)$. Verificou-se, contudo, que as atividades vivenciadas ao longo da graduação reconhecidas pelos estudantes e egressos como interprofissionais, ou seja, as que promovem o compartilhamento e interação entre estudantes de diferentes cursos, apresentaram um percentual menor, chegando a 29,6\% nos estágios curriculares. Essa diferença pode expressar a ausência de consenso sobre o entendimento do que seria uma 'experiência interprofissional' e até um distanciamento desses currículos dos pressupostos teóricos da EIP. Dos estudantes e egressos que vivenciaram a atividade de ensino integradora, 91,9\% percebeu que essa possibilitou o aprendizado com troca e integração de saberes entre os estudantes de diferentes cursos. Em relação à RIPLS, a pesquisa encontra-se na etapa de análise sobre a dimensionalidade da escala (análise fatorial exploratória e análise fatorial confirmatória). Conclusões Atividades de ensino, pesquisa e extensão são reconhecidas pelos estudantes e egressos ao longo de seu curso de graduação. Estágios curriculares e atividades extracurriculares diversas foram as que mais possibilitaram o compartilhamento e interação ativa com estudantes de outros cursos. As disciplinas eletivas ou optativas foram os espaços de ensino mais frequentes para as experiências interprofissionais na graduação. $O$ alto percentual encontrado para a presença de experiências interprofissionais/aprendizagem compartilhada durante o curso de graduação deve ser analisado com cautela, podendo expressar ausência de consenso sobre seu conceito. Espera-se que esta pesquisa possa contribuir com evidências sobre os efeitos de intervenções interprofissionais em atividades de ensino na graduação, trazendo a perspectiva de estudante e egresso.

Descritores: Currículo, Relações interprofissionais, Educação interprofissional, Sistema Único de Saúde 